From the Princess Margaret Hospital Phase II Consortium, Toronto, Canada; Section of Hematology/Oncology, Department of Medicine, University of Chicago, Chicago, IL; The University of North Carolina, Chapel Hill, NC; and National Cancer Institute, Bethesda, MD.

Submitted March 23, 2007; accepted May 14, 2007

Supported by National Cancer Institute Contracts No. N01-CM-62203 and N01-CM-57018-16, and Translational Research Initiative Contract No. 22XS108-09

Presented in part at the 2006 American Society of Clinical Oncology Annual Meeting, June 2-6, 2006, Atlanta, GA.

Authors' disclosures of potential conflicts of interest and author contributions are found at the end of this article.

Address reprint requests to Lillian L. Siu, MD, Department of Medical Oncology and Hematology, Princess Margaret Hospital, University Health Network, 610 University Ave, Suite 5-718,

Toronto, Ontario, M5G 2M9, Canada e-mail: lillian.siu@uhn.on.ca.

C 2007 by American Society of Clinical Oncology

0732-183X/07/2525-3978/\$20.00 DOI: 10.1200/JCO.2007.11.8612

\title{
Phase II Study of Lapatinib in Recurrent or Metastatic Epidermal Growth Factor Receptor and/or erbB2 Expressing Adenoid Cystic Carcinoma and Non-Adenoid Cystic Carcinoma Malignant Tumors of the Salivary Glands
}

Mark Agulnik, Ezra W.E. Cohen, Roger B. Cohen, Eric X. Chen, Everett E. Vokes, Sebastien J. Hotte, Eric Winquist, Scott Laurie, D. Neil Hayes, Janet E. Dancey, Shirley Brown, Gregory R. Pond, Ian Lorimer, Manijeh Daneshmand, James Ho, Ming-Sound Tsao, and Lillian L. Siu

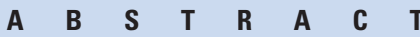

\section{Purpose}

Expression of erbB2 and/or epidermal growth factor receptor (EGFR) is associated with biologic aggressiveness and poor prognosis in malignant salivary gland tumors (MSGTs). This phase II study was conducted to determine the antitumor activity of lapatinib, a dual inhibitor of EGFR and erbB2 tyrosine kinase activity, in MSGTs.

\section{Patients and Methods}

Patients with progressive, recurrent, or metastatic adenoid cystic carcinoma (ACC) immunohistochemically expressing at least 1+ EGFR and/or 2+ erbB2 were treated with lapatinib 1,500 mg daily, in a two-stage cohort. Patients with non-ACC MSGTs were treated as a separate single-stage cohort

\section{Results}

Of 62 patients screened, 29 of 33 (88\%) ACC and 28 of 29 (97\%) non-ACC patients expressed EGFR and/or erbB2. Forty patients with progressive disease were enrolled onto the study. Among 19 assessable ACC patients, there were no objective responses, 15 patients (79\%) had stable disease (SD), nine patients (47\%) had SD $\geq 6$ months, and four patients $(21 \%)$ had progressive disease (PD). For 17 assessable non-ACC patients, there were no objective responses, eight patients $(47 \%)$ had SD, four patients (24\%) had SD $\geq 6$ months, and nine patients (53\%) had PD. The most frequent adverse events were grade 1 to 2 diarrhea, fatigue, and rash. Eight paired tumor biopsies for correlative studies were procured; results did not correlate with clinical outcome.

\section{Conclusion}

Although no responses were observed, lapatinib was well tolerated, with prolonged tumor stabilization of $\geq 6$ months in $36 \%(95 \% \mathrm{Cl}, 21 \%$ to $54 \%)$ of assessable patients. The antitumor effects of lapatinib in MGSTs appear mainly cytostatic, hence evaluation of other molecular targeted agents, or combinations with lapatinib, may be considered. Continued efforts should be made to gain better understanding into the biology of this heterogeneous group of malignancies.

\section{J Clin Oncol 25:3978-3984. (C) 2007 by American Society of Clinical Oncology}

\section{INTRODUCTION}

Malignant salivary gland tumors (MSGTs) account for less than $1 \%$ of all cancers, and $6 \%$ to $7 \%$ of cancers of the head and neck. ${ }^{1-3}$ Adenoid cystic carcinoma histology (ACC) accounts for $11 \%$ and $41 \%$ of major and minor MSGTs, respectively. ACC is treated mainly with surgery and radiation; systemic therapy is reserved for the management of local recurrence no longer amenable to additional local therapy, and in the palliation of symptoms from metastases. Response rates to conventional chemo- therapy are generally low, based on small institutional series, and are not clearly associated with any survival advantage. ${ }^{4,5}$ Unlike ACC, non-ACC MSGTs are a heterogeneous group with distinct histologies and variable biologic behavior. Patients with recurrent or metastatic non-ACC MSGTs may achieve objective response rates ranging from 15\% to $50 \%$ with conventional cytotoxic chemotherapy, but duration of response is typically limited to 6 to 9 months. ${ }^{4,5}$ Given this, patients with progressive ACC and non-ACC MSGT are ideal candidates for trials of investigational new drugs. 
Lapatinib is a dual inhibitor of the tyrosine kinase domains of the epidermal growth factor receptor (EGFR) and erbB2 by interfering with adenosine triphosphate binding, thus blocking autophosphorylation and resultant downstream signaling activities, including cellular proliferation and survival. ${ }^{6}$ In head and neck squamous cell cancers, EGFR expression predicts for poor disease-free and cause-specific survivals. ${ }^{7}$ Overexpression of erbB2 is associated with biologic aggressiveness and poor prognosis in MSGTs. ${ }^{8-13}$ Clinicopathologic studies with limited sample sizes examining the expression of EGFR and erbB2 in MSGTs by immunohistochemistry (IHC) have reported wide variations in frequencies ranging from $0 \%$ to $85 \%{ }^{14-18}$ and $0 \%$ to $100 \%,{ }^{10,12,16,19-30}$ respectively.

This study aimed to evaluate the antitumor activity of lapatinib in recurrent and/or metastatic ACC and other MSGTs with documented IHC expression of EGFR and/or erbB2. We chose to study ACC and non-ACC MSGTs because of the paucity of effective palliative treatments available to both groups and the evidence for target expression in both histologic subtypes by IHC.

\section{PATIENTS AND METHODS}

\section{Patient Eligibility}

Patients $\geq 18$ years of age with histologically or cytologically confirmed ACC or non-ACC MSGTs were potentially eligible if they had $\geq 1+$ EGFR and/or $\geq 2+$ erbB2 expressing tumors, determined by IHC. Patients were required have recurrent and/or metastatic disease not amenable to potentially curative surgery or radiotherapy, and documented disease progression within 6 months of study entry. Progressive disease (PD) was defined as a minimum of $20 \%$ increase in the sum of maximal diameters of measurable disease, the appearance of new lesions, or deterioration in clinical status. Patients were required to have measurable disease according to the Response Evaluation Criteria in Solid Tumors Committee (RECIST) criteria, ${ }^{31}$ and may have had unlimited prior therapy up to 4 weeks before study enrollment. Other key eligibility criteria included Eastern Cooperative Oncology Group performance status $\leq 2$; life expectancy of at least 12 weeks; normal organ and marrow function (total bilirubin within normal limits, AST and ALT $\leq 2.5 \times$ upper limit of normal, creatinine within normal limits or creatinine clearance $\geq 60$ $\mathrm{mL} / \mathrm{min} / 1.73 \mathrm{~m}^{2}$, leukocytes $\geq 3,000 / \mu \mathrm{L}$, absolute neutrophil count $\geq 1,500$ / $\mu \mathrm{L}$, and platelets $\geq 100,000 / \mu \mathrm{L}$ ); and normal cardiac left ventricular ejection fraction (LVEF) by multiple-gated acquisition scan. Patients were required to undergo tumor biopsy once before (between days -7 and 0 ) and once during investigational therapy (between days 14 and 21) unless there was a medical contraindication. Patients were excluded if they had prior treatment with an EGFR or erbB2 inhibitor. Participants provided written informed consent before study enrollment; the study was approved by all local research ethics committees of participating centers.

\section{Study Therapy and Dose Modifications}

Study treatment consisted of lapatinib 1,500 mg orally once daily on an empty stomach. Lapatinib was supplied by the National Cancer Institute, Division of Cancer Treatment and Diagnosis, Cancer Therapy Evaluation Program. Cycle length was 28 days and treatment was continued until disease progression, unacceptable toxicity, patient refusal, or physician's decision to withdraw the patient. Patients were assessed for objective response, classified by RECIST, ${ }^{31}$ every 8 weeks.

Toxicity was graded according to National Cancer Institute Common Terminology Criteria for Adverse Events, version 3.0. For intolerable grade 2 or for grade 3 or 4 toxicity, lapatinib was withheld until the toxicity was grade $\leq 1$ and then resumed at $1,500 \mathrm{mg} / \mathrm{d}$ for the first intolerable grade 2 toxicity, or $1,000 \mathrm{mg} / \mathrm{d}$ for subsequent intolerable grade 2 toxicity and any grade 3 or 4 toxicity. A second dose reduction to $750 \mathrm{mg} / \mathrm{d}$ was allowed. Necessity for a third dose reduction, persistent toxicity after 3 weeks off lapatinib, grade 3 or 4 interstitial pneumonitis, or left ventricular systolic dysfunction would mandate discontinuation of study therapy.

\section{Archival Specimens}

Histologies of all patients were reviewed centrally by a blinded pathologist (M.T.). Two (5\%) discrepancies were identified when compared with original pathology reports.

Screening for EGFR and erbB2 expression, using archival paraffin samples or fresh tumor biopsies, was measured by IHC. For EGFR, IHC was performed using a standard avidin-biotin technique. The incubation time was 1 hour with the primary mouse monoclonal antibody (clone 31G7, 1:50 dilution; Zymed Laboratories, South San Francisco, CA). For erbB2, the sections were subjected to antigen retrieval by boiling in citrate buffer followed by incubation with the primary antibody (rabbit antip185/HER-2, Herceptest; DAKO AS, Copenhagen, Denmark). After sections were washed, they were incubated for 20 minutes each with biotinylated secondary antibody, followed by streptavidin-horseradish peroxidase using the Multi-Species Ultra Streptavidin Kit (Signet Laboratories, Dedham, MA). The slides were developed for 5 minutes using the NovaRed substrate kit (Vector Laboratories, Burlingame, $\mathrm{CA}$ ), and then counterstained with Mayer's hematoxylin. Slides were scored on a 0 to $3+$ scale: 0 , staining in less than $10 \%$ of tumor cells or no staining; $1+$, faint and partial membrane staining in $\geq 10 \%$ of tumor cells; $2+$, weak to moderate complete membrane staining in $\geq 10 \%$ of tumor cells; or $3+$, moderate to strong complete membrane staining in $\geq 10 \%$ of tumor cells.

\section{Correlative Studies on Paired Tumor Specimens}

Biomarkers related to EGFR and erbB2 and their associated pathways were analyzed in tumor tissues using a colorimetric IHC technique. Phosphorylation of EGFR activates downstream signaling pathways that include RasRaf-mitogen-activated protein kinase kinase extracellular signal-regulated kinase (ERK), phosphatidylinositol 3-kinase/Akt, and the signal transducer and activator of transcription-3 (STAT-3) pathways. Ki-67 is an index of cellular proliferation, p27 is a cell cycle regulatory protein, and insulin-like growth factor receptor-1 (IGFR-1) and STAT-3 are signaling proteins potentially involved in resistance to inhibition of the EGFR/erbB2 pathway. Phosphorylation denotes the activation state of the cellular phosphoproteins under evaluation. Paired tumor biopsies were assessed by IHC for EGFR, phosphorylated (p) -EGFR, erbB2, p-erbB2, p-ERK, p-Akt, p27, Ki-67, IGFR-1, and p-STAT-3.

Frozen samples were embedded in Cryomatrix embedding resin (Thermo Shandon, Pittsburgh, PA) and $5-\mu \mathrm{m}$ sections were prepared using a cryostat. Fixation, permeabilization, and staining for specific antigens were performed, as described previously. ${ }^{32}$ Because of a lack of staining with frozen samples for p-EGFR, p-erbB2, and p-Akt, the samples were fixed in formalin and processed into paraffin blocks to retest for these three markers. Primary antibodies used for IHC are listed in Appendix Table A1 (online only).

Scoring was done similar to the archival specimens stained for EGFR and erbB2. For p27, cytoplasmic and nuclear staining was scored separately. p-ERK scoring was based on the percentage of tumor cells positive for cytoplasmic staining. Both Ki-67 and p-STAT-3 scoring were based on the percentage of tumor cells positive for nuclear staining.

\section{Statistical Considerations}

The primary objective of this study was to determine the objective response rate (complete responses and partial responses [PRs]) of lapatinib in ACC. Secondary objectives were to evaluate the duration of response; rate and duration of stable disease (SD); progression-free, median, and overall survival (OS) rates; and safety and tolerability of lapatinib in this population. A twostage design was used for the ACC cohort, according to Simon. ${ }^{33}$ The null hypothesis assumed that the response rate was less than $5 \%$ and the alternative hypothesis assumed that the response rate was at least $20 \%$. The design allowed enrollment of 12 assessable patients in the first stage. If one response was observed, an additional 25 assessable patients were to be enrolled. Assessment of the activity of lapatinib in non-ACC MSGTs was exploratory without a predetermined study design, with up to 30 patients planned.

For correlative samples, descriptive statistics were used to summarize each marker outcome at pretreatment, during treatment, and any difference between the two. Wilcoxon signed rank test was used to assess statistically 
significant changes in marker value from pre- to during-treatment biopsy. Fisher's exact tests assessed whether pretreatment marker values, or the change in marker value, predicted SD as best response. For this analysis, optimal splits of the marker were performed to maximize statistical power. Whisker plots and bar graphs were used to demonstrate marker values pre- and duringtreatment. Cox proportional hazards regression methods assessed whether pretreatment marker values, or change in markers, were predictive of time to progression (TTP). No investigation of predictors of OS was conducted. All tests were two sided and exact $P$ values are reported throughout.

\section{RESULTS}

\section{Patients and Treatment}

Between November 2004 and March 2006, 20 patients with ACC and 20 patients with non-ACC MSGTs were enrolled at seven centers in Canada and the United States. Fifty-seven (92\%) of 62 screened patients were positive for EGFR and/or erbB2. Of the 57 patients, nine were found to be ineligible for the study and eight patients declined participation. Of 40 patients enrolled onto the study, 39 and 36 were assessable for toxicity and objective response, respectively. One nonACC patient had rapidly progressive disease after enrollment, never received study drug, and was excluded from additional analysis. Three patients, one with ACC and two with non-ACC, were not assessable for response but were included in the toxicity analysis; one had evidence of brain metastasis within 7 days of starting study treatment, one had a prior active malignancy within 5 years of study entry (and was ineligible per protocol), and one was withdrawn from study after 7 days to be treated with a protocol-prohibited medication (proton pump inhibitor). Patient characteristics are listed in Table 1.

\section{Response and Survival}

Of 19 assessable ACC patients, four had PD within two cycles. Of the 15 patients with SD after two cycles of treatment, six patients experienced disease progression within four cycles, and seven patients experienced disease progression after 6, 7, 10, 13, 14, 20, and 21 cycles, respectively. For the remaining two patients, one patient with SD was removed from study after six cycles due to an asymptomatic decrease in LVEF, and one remains on treatment and has received 21 cycles of therapy.

Of 17 assessable non-ACC MSGT patients, one died at the end of cycle 2 due to disease progression/pneumonia before objective response evaluation, seven had PD within two cycles, and two with objective SD were taken off therapy after two cycles (one for symptomatic progression and one at the discretion of the local investigator). Of seven patients with SD after two cycles, three patients experienced disease progression before cycle 5 , and four patients experienced disease progression after $6,9,10$, and 20 cycles, respectively.

Although no objective responses were observed (Table 1), a subset of patients had a reduction in measurable disease (Fig 1). When analyzed together, 13 patients had documented SD $\geq 6$ months (Table 2). For these patients, the mean TTP before initiating therapy was 3 months, with a range of 2 to 6 months.

For all patients, the median follow-up duration, OS, and progression-free survival (PFS) was 15.8 months, not reached, and 3.4 months (95\% CI, 2.1 to 5.3 months), respectively. For ACC, the median OS duration and 6-month OS rate were not reached and $90.0 \%$ (95\% CI, $77.8 \%$ to $100 \%$ ), respectively, whereas the median PFS duration and 6-month PFS rate were 3.5 months (95\% CI, 3.1 to 12.7 months) and $35.0 \%$ (95\% CI, $19.3 \%$ to $63.6 \%$ ) respectively. For
Table 1. Patient Characteristics for Both $A C C$ and Non-ACC Cohorts

\begin{tabular}{|c|c|c|c|c|}
\hline \multirow[b]{2}{*}{ Characteristic } & \multicolumn{2}{|c|}{ ACC } & \multicolumn{2}{|c|}{ Non-ACC } \\
\hline & $\begin{array}{l}\text { No. of } \\
\text { Patients }\end{array}$ & $\%$ & $\begin{array}{l}\text { No. of } \\
\text { Patients }\end{array}$ & $\%$ \\
\hline No. of patients & 20 & 100 & 19 & 100 \\
\hline \multicolumn{5}{|l|}{ Age, years } \\
\hline Median & \multicolumn{2}{|c|}{52} & \multicolumn{2}{|c|}{64} \\
\hline Range & \multicolumn{2}{|c|}{ 38-72 } & \multicolumn{2}{|c|}{$45-80$} \\
\hline \multicolumn{5}{|l|}{ Sex } \\
\hline Male & 12 & 60 & 16 & 84 \\
\hline Female & 8 & 40 & 3 & 16 \\
\hline \multicolumn{5}{|l|}{ Performance status } \\
\hline 0 & 8 & 40 & 10 & 53 \\
\hline 1 & 11 & 55 & 9 & 47 \\
\hline 2 & 1 & 5 & 0 & \\
\hline \multicolumn{5}{|l|}{ Disease status at study entry } \\
\hline Locoregionally recurrent & 3 & 15 & 4 & 21 \\
\hline Metastatic & 15 & 75 & 13 & 68 \\
\hline Both & 2 & 10 & 2 & 11 \\
\hline \multicolumn{5}{|l|}{ Histology } \\
\hline ACC & 20 & 100 & 0 & \\
\hline Adenocarcinoma & 0 & & 7 & 35 \\
\hline Large/salivary duct carcinoma & 0 & & 4 & 20 \\
\hline Squamous cell carcinoma & 0 & & 3 & 15 \\
\hline Undifferentiated carcinoma & 0 & & 3 & 15 \\
\hline Mucoepidermoid carcinoma & 0 & & 2 & 10 \\
\hline Acinic cell carcinoma & 0 & & 1 & 5 \\
\hline \multicolumn{5}{|l|}{ IHC results } \\
\hline EGFR positive/erbB2 positive & 1 & 5 & 8 & 40 \\
\hline EGFR positive /erbB2 negative & 19 & 95 & 12 & 60 \\
\hline \multicolumn{5}{|l|}{ EGFR-positive scores } \\
\hline 0 & 0 & & 0 & \\
\hline $1+$ & 5 & 25 & 3 & 15 \\
\hline $2+$ & 10 & 50 & 6 & 30 \\
\hline $3+$ & 5 & 25 & 11 & 55 \\
\hline \multicolumn{5}{|l|}{ erbB2-positive scores } \\
\hline 0 & 13 & 65 & 7 & 35 \\
\hline $1+$ & 6 & 30 & 5 & 25 \\
\hline $2+$ & 1 & 5 & 3 & 15 \\
\hline $3+$ & 0 & & 5 & 25 \\
\hline \multicolumn{5}{|l|}{ No. of prior regimens } \\
\hline 0 & 11 & 55 & 9 & 47 \\
\hline 1 & 4 & 20 & 3 & 16 \\
\hline 2 & 4 & 20 & 5 & 26 \\
\hline 3 & 1 & 5 & 2 & 11 \\
\hline \multicolumn{5}{|l|}{ Prior therapy } \\
\hline Chemotherapy & 9 & 45 & 10 & 53 \\
\hline Radiation & 18 & 90 & 17 & 89 \\
\hline Target/nontarget lesions & & & & \\
\hline Median & & $/ 1$ & & $1 / 1$ \\
\hline Range & & $/ 0-5$ & & /0-10 \\
\hline Lung & $16 / 13$ & & $13 / 11$ & \\
\hline Liver & 2/1 & & $3 / 2$ & \\
\hline Nodes & $4 / 1$ & & $7 / 4$ & \\
\hline Abdomen & $0 / 1$ & & $0 / 0$ & \\
\hline Other & $5 / 1$ & & $4 / 4$ & \\
\hline Best response to lapatinib treatme & & & & \\
\hline $\mathrm{PR}$ & 0 & & 0 & \\
\hline $\mathrm{SD} \geq 6$ months & 9 & 45 & 4 & 21 \\
\hline $\mathrm{SD}<6$ months & 6 & 30 & 4 & 21 \\
\hline PD & 4 & 20 & 9 & 47 \\
\hline NA & 1 & 5 & 2 & 11 \\
\hline
\end{tabular}

Abbreviations: ACC, adenoid cystic carcinoma; EGFR, epidermal growth factor receptor; $\mathrm{IHC}$, immunohistochemistry; PR, partial response; $\mathrm{SD}$, stable disease; PD, progressive disease; NA, not assessable. 


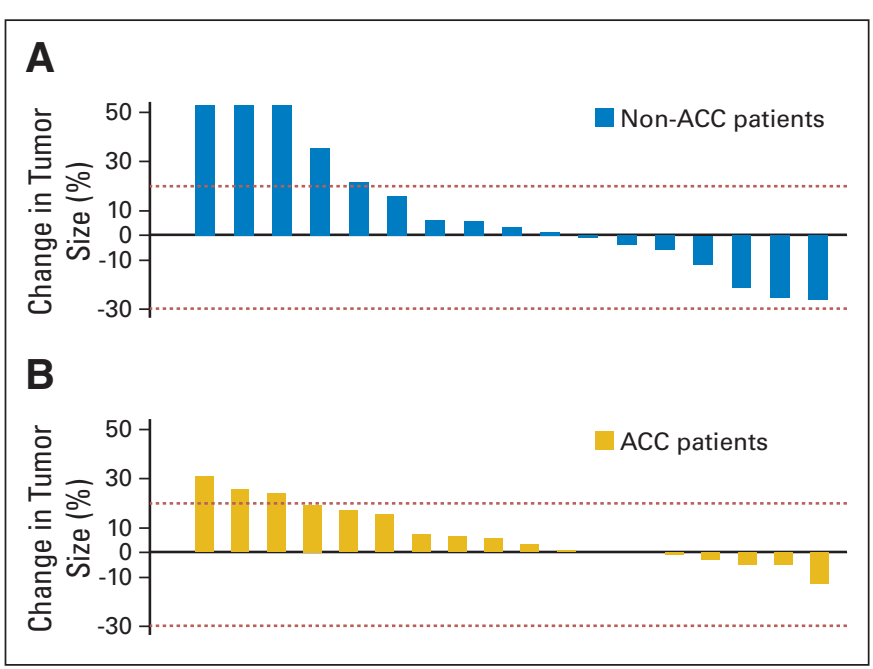

Fig 1. Maximal percentage of tumor reduction for target lesions by Response Evaluation Criteria in Solid Tumors Committee (RECIST). Percentages are calculated using the summed unidimensional measurements of target lesions per RECIST.

non-ACC, the median OS duration and 6-month OS rate were 13.8 months ( $95 \%$ CI, 7.3 to not reached) and $69.3 \%$ (95\% CI, 50.1\% to 95.9\%), respectively, whereas the median PFS duration and 6-month PFS rate were 2.1 months (95\% CI, 1.6 to 8.3 months) and $19.9 \%$ ( $95 \%$ CI, 7.3\% to $54.0 \%$ months), respectively (Fig 2 ).

\section{Correlative Studies}

Archival specimens. The percentage of assessable patients with $\mathrm{SD} \geq 6$ months in subgroups based on EGFR or erbB2 expression in archival specimens suggested a positive correlation as follows: $1+$ to $2+$ EGFR (seven of $23 ; 30 \%$ ) versus $3+$ EGFR (six of $13 ; 46 \%$ ); 0 to $2+$ erbB2 (10 of 32; 31\%) versus $3+$ erbB2 (three of four; 75\%). Interestingly, three of three patients (100\%) with 3+ EGFR and 3+ erbB2 staining in archival tumor specimens had $\mathrm{SD} \geq 6$ months (Table 2).

\begin{tabular}{|lrcccc}
\hline \multicolumn{5}{l}{ Table 2. Characteristics for Patients With Stable Disease Beyond 6 Months } \\
\hline Histology & $\begin{array}{c}\text { No. of } \\
\text { Cycles }\end{array}$ & EGFR & erbB2 & $\begin{array}{c}\text { Prior TTP } \\
\text { (months) }\end{array}$ \\
\hline ACC & 21 & $2+$ & 0 & 3 \\
ACC & 6 & $1+$ & 0 & 3 \\
ACC & 6 & $3+$ & $1+$ & 3 \\
ACC & 21 & $3+$ & $1+$ & 3 \\
ACC & 7 & $2+$ & $1+$ & 3 \\
ACC & 19 & $1+$ & 0 & 6 \\
ACC & 10 & $2+$ & $1+$ & 2 \\
ACC & 14 & $2+$ & 0 & 4 \\
ACC & 13 & $3+$ & 0 & 3 \\
Undifferentiated carcinoma & 6 & $1+$ & $1+$ & 3 \\
Adenocarcinoma & 20 & $3+$ & $3+$ & 3 \\
Squamous cell carcinoma & 9 & $3+$ & $3+$ & 5 \\
Undifferentiated carcinoma & 10 & $3+$ & $3+$ & 6 \\
\hline
\end{tabular}

Abbreviations: ACC, adenoid cystic carcinoma; EGFR, epidermal growth factor receptor; TTP, time to progression.
A

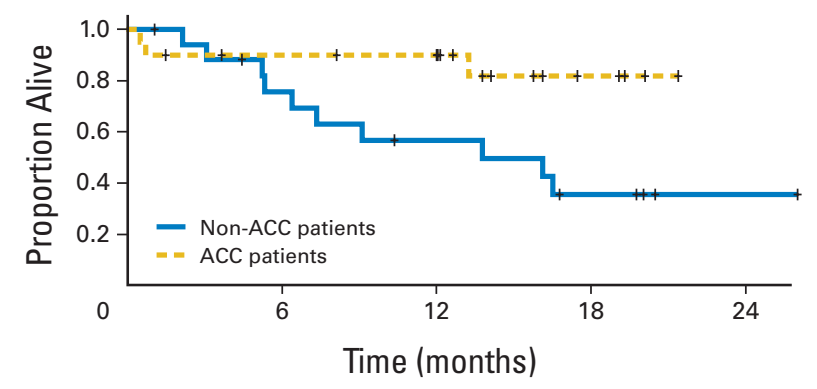

B

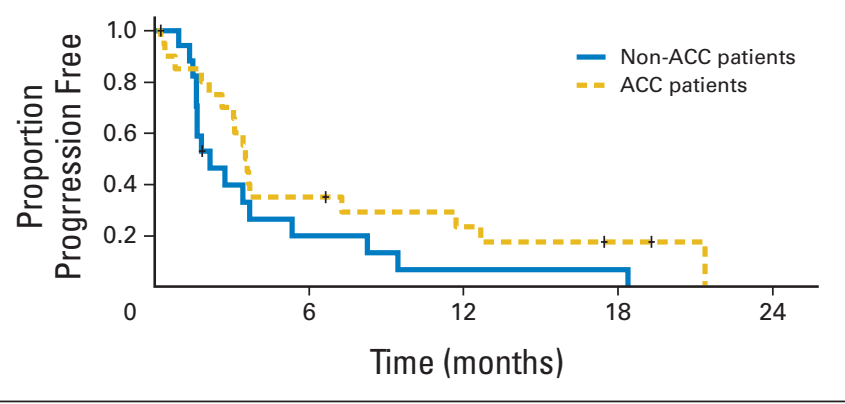

Fig 2. Survival and time to progression for patients with adenoid cystic carcinoma (ACC) and non-ACC malignant salivary gland tumors treated with lapatinib.

\section{Paired Tumor Biopsies}

Pretreatment and during-treatment biopsies were taken from 22 and 16 patients, respectively. Only eight patients had sufficient tumor cells on microscopic evaluation in both samples (Fig 3). A trend toward decreased p-Akt, decreased Ki-67, and increased p-STAT-3 was observed, but small numbers precluded any conclusions. There were no statistically significant associations between marker assessment and clinical outcome, nor were they of predictive value.

\section{Toxicity}

Lapatinib was tolerated well by most patients (Table 3). The majority of adverse events were grade 1 to 2 in intensity. Two grade 4 adverse events occurred: a secondary malignancy (laryngeal cancer) and laryngeal edema. Neither was believed to be related to lapatinib. Three patients died while on study, two as a result of disease progression, and one as a result of an intercurrent pneumonia.

Two patients with ACC had an asymptomatic reduction in LVEF from baseline of at least $10 \%$. One had a baseline LVEF of $76 \%$ that decreased to $60 \%, 44 \%$, and $55 \%$ after two, four, and six cycles, respectively. A second patient had a baseline LVEF of $62 \%$ that decreased to $51 \%$ after two cycles; LVEF values on the subsequent 11 evaluations ranged from $54 \%$ to $65 \%$.

\section{DISCUSSION}

Salivary gland cancers are a heterogeneous group with varied natural history, aggressiveness, and prognosis. Given that EGFR or ErB2 status may be linked to a poor prognosis, lapatinib, an inhibitor against these targets, may benefit a group of patients with MSGT. Although no objective responses were observed, prolonged SD beyond 6 months 


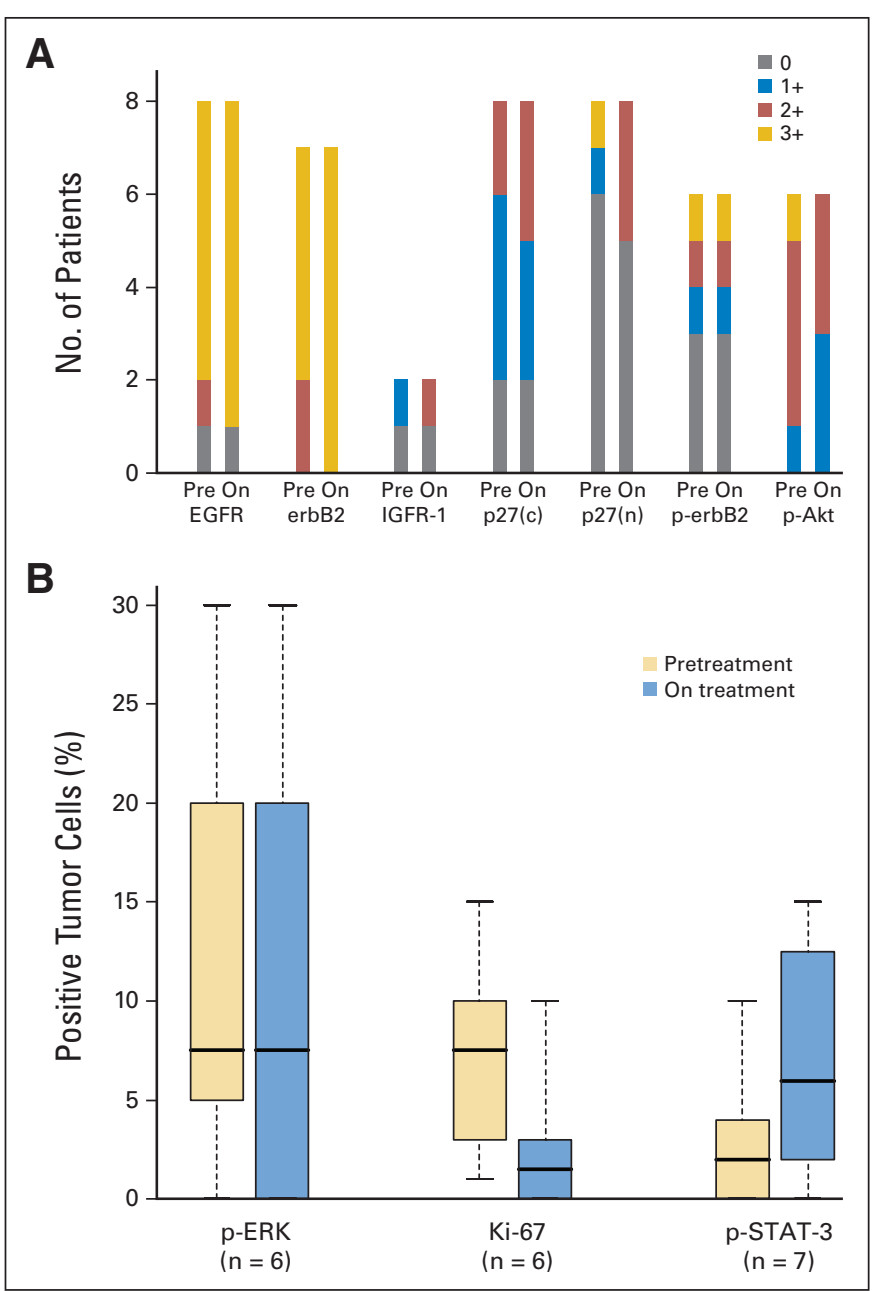

Fig 3. Pretreatment (pre) and during-treatment (on) tumor biopsies from the eight paired samples available for assessment. (A) Bar graphs illustrate marker values for epidermal growth factor receptor (EGFR), erbB2, insulin-like growth factor receptor-1 (IGFR-1), p27, phosphorylated (p-) erbB2, p-Akt. (B) Whisker plots illustrate marker values for extracellular signal-regulated kinase ( $p$-ERK), $\mathrm{Ki}-67$, and signal transducer and activator of transcription-3 (p-STAT-3). Staining was poor for p-EGFR and thus this marker was not included in (B).

was observed in $13(36 \%)$ of 36 assessable patients with PD before starting therapy.

Recent trials of targeted therapies in patients with advanced ACC have reported variable results. Imatinib (which inhibits the c-KIT tyrosine kinase) and gefitinib (which inhibits the EGFR tyrosine kinase) have been evaluated. ${ }^{34-40}$ Four phase II studies and two case reports have evaluated imatinib in 45 patients with ACC. Three reported responses have been documented. ${ }^{34,40}$ Although disease stabilization was documented in studies of imatinib and gefitinib, disease progression as a criterion for study entry was not typically required, and therefore stabilization may in fact reflect the relatively indolent natural course of the disease. The largest of these trials, reported previously by our group, ${ }^{39}$ evaluated the use of imatinib in 16 patients. The median TTP on that study was 2.3 months compared with 3.5 months for the ACC patients reported in the present trial. Although direct comparisons across two different studies are not valid, they may be of exploratory value in a rare disease such as ACC. This caveat notwithstanding, it would seem that treatment with lapatinib may be
Table 3. Toxicities Considered at Least Possibly Related to Lapatinib

\begin{tabular}{|c|c|c|c|c|c|c|}
\hline Toxicity & $\begin{array}{c}\text { No. of } \\
\text { Patients } \\
(n=39)\end{array}$ & $\%$ & $\begin{array}{c}\text { Worst } \\
\text { Grade, } \\
\text { Any } \\
\text { Patient }\end{array}$ & $\begin{array}{c}\text { No. of } \\
\text { Cycles } \\
(n=233)\end{array}$ & $\%$ & $\begin{array}{l}\text { No. of Cycles } \\
\text { With Grade } 3 \\
\text { or } 4 \text { Toxicity } \\
\quad(n=233)\end{array}$ \\
\hline \multicolumn{7}{|l|}{ Nonhematologic } \\
\hline Diarrhea & 24 & 62 & 2 & 103 & 44 & 0 \\
\hline Rash (acneiform) & 19 & 49 & 2 & 67 & 29 & 0 \\
\hline Fatigue & 16 & 41 & 3 & 86 & 37 & 1 \\
\hline Nausea & 11 & 28 & 1 & 52 & 22 & 0 \\
\hline Dry skin & 8 & 21 & 1 & 33 & 14 & 0 \\
\hline Pruritus & 5 & 13 & 1 & 31 & 13 & 0 \\
\hline ALT & 5 & 13 & 2 & 17 & 7 & 0 \\
\hline AST & 5 & 13 & 2 & 17 & 7 & 0 \\
\hline Mucositis & 5 & 13 & 1 & 17 & 7 & 0 \\
\hline Hyperglycemia & 5 & 13 & 2 & 9 & 4 & 0 \\
\hline Headache & 4 & 10 & 3 & 26 & 11 & 19 \\
\hline Creatinine & 4 & 10 & 1 & 13 & 6 & 0 \\
\hline Dysgeusia & 4 & 10 & 2 & 13 & 6 & 0 \\
\hline Vomiting & 4 & 10 & 2 & 5 & 2 & 0 \\
\hline Alopecia & 3 & 8 & 1 & 25 & 11 & 0 \\
\hline Rash (desquamation) & 3 & 8 & 2 & 10 & 4 & 0 \\
\hline Dyspepsia & 3 & 8 & 2 & 9 & 4 & 0 \\
\hline Pain & 3 & 8 & 2 & 5 & 2 & 0 \\
\hline \multicolumn{7}{|l|}{ Hematologic } \\
\hline Anemia & 5 & 13 & 1 & 21 & 9 & 0 \\
\hline Leukopenia & 4 & 10 & 1 & 6 & 3 & 0 \\
\hline Neutropenia & 4 & 10 & 2 & 6 & 3 & 0 \\
\hline Lymphopenia & 3 & 8 & 2 & 14 & 6 & 0 \\
\hline Thrombocytopenia & 2 & 5 & 1 & 10 & 4 & 0 \\
\hline
\end{tabular}

associated with a more prolonged TTP than treatment with imatinib. Of note, in contrast to our prior study with imatinib, our current study with lapatinib enrolled only patients with documented PD. Disease stabilization may represent more meaningful biologic activity in such a patient population.

In addition to imatinib and gefitinib, other targeted agents have been investigated in this disease. A phase II study of trastuzumab in patients with advanced or metastatic MSGTs confirmed one PR and an overall median TTP of 4.2 months. ${ }^{41}$ A phase II trial of bortezomib in patients with incurable ACC reported a median PFS of 8.5 months in patients with $\mathrm{PD}$ within 9 months of study entry. ${ }^{42}$ In a phase I trial of axitinib (AG-013736), a potent small molecule tyrosine kinase inhibitor of all known vascular endothelial growth factor receptors, platelet-derived growth factor receptor beta, and c-KIT, one patient with ACC experienced a PR. ${ }^{43}$

Identifying relevant proliferation and antiapoptosis survival pathways in malignant cells may inform therapeutic options based on tumor biology rather than histology alone. Preclinical data have shown the effects of lapatinib on human tumor cell lines. ${ }^{44}$ Although inhibition of EGFR resulted preferentially in cell growth arrest, inhibition of erbB2 yielded both growth arrest and cell death. In a phase I study of lapatinib, all patients achieving PR had tumors that overexpressed erbB2, whereas pretreatment EGFR status did not discriminate between responders and nonresponders. ${ }^{45}$ In this regard, it is of interest that among our patients with non-ACC MSGTs, all three patients with $3+$ coexpressions of EGFR and erbB2 achieved SD $\geq 6$ months. This observation may suggest greater therapeutic effect when there is a high degree of marker expression. Given that only one 
patient with ACC expressed erbB2 at high levels in our study, conclusions based on marker status for those patients are impossible. Despite our desire to identify biologic pathways that might predict or correlate with response, too few viable samples were procured. The challenge of producing meaningful correlative study data is likely a reflection of both technical issues and heterogeneity across patients. Most of the patients on this study had lung metastases, for example, that are often difficult to biopsy safely with adequate tissue acquisition. The choice of tissue fixation is also critical in the demonstration and evaluation of protein expression by IHC. ${ }^{46}$ Our results may have been affected negatively by the use of fresh frozen as opposed to formalin-fixed specimens, as others have reported previously. ${ }^{46}$

Stage I of the ACC protocol over-accrued patients because of the overwhelming interest of investigators and patients participating in this trial. Given that no objective responses were seen in either cohort, the second stage of the ACC arm did not open and the non-ACC arm was also terminated. Although there were no objective responses, a significant rate of disease stabilization seen in a group of patients with PD at study entry is of clinical relevance. The antitumor activity of lapatinib in MSGTs is believed to be primarily cytostatic. With this in mind, additional evaluation of molecular targeted therapies in this disease optimally would be performed using a novel study design with progression-based rather than response-based end points, as well as mandating assessment of disease progression by RECIST within 6 months of study entry. This study illustrates further that clinical trials in
MSGTs can accrue successfully based on collaborative efforts by multiple groups.

\section{AUTHORS' DISCLOSURES OF POTENTIAL CONFLICTS} OF INTEREST

The author(s) indicated no potential conflicts of interest.

\section{AUTHOR CONTRIBUTIONS}

Conception and design: Mark Agulnik, Eric X. Chen, Janet E. Dancey, Lillian L. Siu

Financial support: Janet E. Dancey

Administrative support: Janet E. Dancey, Shirley Brown

Provision of study materials or patients: Ezra W.E. Cohen, Roger B.

Cohen, Eric X. Chen, Everett E. Vokes, Sebastien J. Hotte, Eric Winquist, Scott Laurie, D. Neil Hayes, Lillian L. Siu

Collection and assembly of data: Shirley Brown, Ian Lorimer, Manijeh Daneshmand, James Ho, Ming-Sound Tsao

Data analysis and interpretation: Mark Agulnik, Gregory Pond, Ian Lorimer, Manijeh Daneshmand, James Ho, Ming-Sound Tsao, Lillian L. Siu

Manuscript writing: Mark Agulnik, Lillian L. Siu

Final approval of manuscript: Mark Agulnik, Ezra W.E. Cohen, Roger

B. Cohen, Eric X. Chen, Everett E. Vokes, Sebastien J. Hotte, Eric

Winquist, Scott Laurie, D. Neil Hayes, Janet E. Dancey, Shirley Brown,

Gregory Pond, Ian Lorimer, Manijeh Daneshmand, James Ho,

Ming-Sound Tsao, Lillian L. Siu

\section{REFERENCES}

1. Hocwald E, Korkmaz H, Yoo GH, et al: Prognostic factors in major salivary gland cancer. Laryngoscope 111:1434-1439, 2001

2. Speight PM, Barrett AW: Salivary gland tumours. Oral Dis 8:229-240, 2002

3. Spiro $\mathrm{RH}$ : Management of malignant tumors of the salivary glands. Oncology (Williston Park) 12:671-680, 1998; discussion 683

4. Agulnik M, Siu LL: An update on the systemic therapy of malignant salivary gland cancers: Role of chemotherapy and molecular targeted agents. Curr Med Chem Anticancer Agents 4:543-551, 2004

5. Laurie SA, Licitra L: Systemic therapy in the palliative management of advanced salivary gland cancers. J Clin Oncol 24:2673-2678, 2006

6. Shewchuk L, Hassell A, Wisely B, et al: Binding mode of the 4-anilinoquinazoline class of protein kinase inhibitor: X-ray crystallographic studies of 4-anilinoquinazolines bound to cyclin-dependent kinase 2 and p38 kinase. J Med Chem 43:133-138, 2000

7. Rubin Grandis J, Melhem MF, Gooding WE, et al: Levels of TGF-alpha and EGFR protein in head and neck squamous cell carcinoma and patient survival. J Natl Cancer Inst 90:824-832, 1998

8. Giannoni $C$, el-Naggar AK, Ordonez NG, et al: C-erbB-2/neu oncogene and $\mathrm{Ki}-67$ analysis in the assessment of palatal salivary gland neoplasms. Otolaryngol Head Neck Surg 112:391-398, 1995

9. Nagler RM, Kerner $\mathrm{H}$, Ben-Eliezer $\mathrm{S}$, et al: Prognostic role of apoptotic, Bcl-2, c-erbB-2 and p53 tumor markers in salivary gland malignancies. Oncology 64:389-398, 2003

10. Press MF, Pike MC, Hung G, et al: Amplification and overexpression of HER-2/neu in carcinomas of the salivary gland: Correlation with poor prognosis. Cancer Res 54:5675-5682, 1994
11. Stenman G, Sandros J, Nordkvist A, et al: Expression of the ERBB2 protein in benign and malignant salivary gland tumors. Genes Chromosomes Cancer 3:128-135, 1991

12. Sugano $S$, Mukai $K$, Tsuda $H$, et al: Immunohistochemical study of c-erbB-2 oncoprotein overexpression in human major salivary gland carcinoma: An indicator of aggressiveness. Laryngoscope 102: 923-927, 1992

13. Sun $H$, Wu $S$, Ouyang J: Expression of C-erbB-2 oncogene mRNA in salivary gland tumors. Zhonghua Kou Qiang Yi Xue Za Zhi 34:289-291, 1999

14. Chen CH, Li BY, Wan JT, et al: Expression of epidermal growth factor in salivary adenoid cystic carcinoma. Proc Natl Sci Counc Repub China B 25:90-96, 2001

15. Fan CY, Melhem MF, Hosal AS, et al: Expression of androgen receptor, epidermal growth factor receptor, and transforming growth factor alpha in salivary duct carcinoma. Arch Otolaryngol Head Neck Surg 127:1075-1079, 2001

16. Shintani S, Funayama $T$, Yoshihama $Y$, et al: Expression of c-erbB family gene products in adenoid cystic carcinoma of salivary glands: An immunohistochemical study. Anticancer Res 15: 2623-2626, 1995

17. Vered M, Braunstein E, Buchner A: Immunohistochemical study of epidermal growth factor receptor in adenoid cystic carcinoma of salivary gland origin. Head Neck 24:632-636, 2002

18. Yamada K, Iwai K, Okada $Y$, et al: Immunohistochemical expression of epidermal growth factor receptor in salivary gland tumours. Virchows Arch A Pathol Anat Histopathol 415:523-531, 1989

19. Cho KJ, Kim JY, Lee SS, et al: Mucoepidermoid carcinoma of the salivary gland: A clinico-pathologic and immunohistochemical study for c-erbB-2 oncoprotein. J Korean Med Sci 12:499-504, 1997
20. Barnes $L$, Rao $U$, Contis $L$, et al: Salivary duct carcinoma: Part II. Immunohistochemical evaluation of 13 cases for estrogen and progesterone receptors, cathepsin D, and c-erbB-2 protein. Oral Surg Oral Med Oral Pathol 78:74-80, 1994

21. Cho KJ, Lee SS, Lee YS: Proliferating cell nuclear antigen and c-erbB-2 oncoprotein expression in adenoid cystic carcinomas of the salivary glands. Head Neck 21:414-419, 1999

22. Dori $S$, Vered $M$, David $R$, et al: HER2/neu expression in adenoid cystic carcinoma of salivary gland origin: An immunohistochemical study. J Oral Pathol Med 31:463-467, 2002

23. Etges A, Pinto DS Jr, Kowalski LP, et al: Salivary duct carcinoma: Immunohistochemical profile of an aggressive salivary gland tumour. J Clin Pathol 56:914-918, 2003

24. Felix A, El-Naggar AK, Press MF, et al: Prognostic significance of biomarkers (c-erbB-2, p53, proliferating cell nuclear antigen, and DNA content) in salivary duct carcinoma. Hum Pathol 27:561-566, 1996

25. Glisson B, Colevas AD, Haddad R, et al: HER2 expression in salivary gland carcinomas: Dependence on histological subtype. Clin Cancer Res 10:944-946, 2004

26. Kärjä $V$, Syrjänen $S$, Kataja $V$, et al: C-erbB-2 oncogene expression in salivary gland tumours. ORL J Otorhinolaryngol Relat Spec 56:206-212, 1994

27. Kernohan NM, Blessing $K$, King $G$, et al: Expression of c-erbB-2 oncoprotein in salivary gland tumours: An immunohistochemical study. J Pathol 163:77-80, 1991

28. Martinez-Barba E, Cortes-Guardiola JA, MinguelaPuras A, et al: Salivary duct carcinoma: Clinicopathological and immunohistochemical studies. J Craniomaxillofac Surg 25:328-334, 1997 
29. Skálová A, Starek I. Kucerova V, et al: Salivary duct carcinoma: A highly aggressive salivary gland tumor with HER-2/neu oncoprotein overexpression. Pathol Res Pract 197:621-626, 2001

30. Skálová A, Starek I, Vanecek T, et al: Expression of HER-2/neu gene and protein in salivary duct carcinomas of parotid gland as revealed by fluorescence in-situ hybridization and immunohistochemistry. Histopathology 42:348-356, 2003

31. Therasse P, Arbuck SG, Eisenhauer EA, et al: New guidelines to evaluate the response to treatment in solid tumors: European Organization for Research and Treatment of Cancer, National Cancer Institute of the United States, National Cancer Institute of Canada. J Natl Cancer Inst 92:205-216, 2000

32. Daneshmand M, Parolin DA, Hirte HW, et al: A pharmacodynamic study of the epidermal growth factor receptor tyrosine kinase inhibitor ZD1839 in metastatic colorectal cancer patients. Clin Cancer Res 9:2457-2464, 2003

33. Simon R: Optimal two-stage designs for phase II clinical trials. Control Clin Trials 10:1-10, 1989

34. Alcedo JC, Fabrega JM, Arosemena JR, et al: Imatinib mesylate as treatment for adenoid cystic carcinoma of the salivary glands: Report of two successfully treated cases. Head Neck 26:829-831, 2004

35. Faivre S, Raymond E, Casiraghi O, et al: Imatinib mesylate can induce objective response in progressing, highly expressing KIT adenoid cystic carcinoma of the salivary glands. J Clin Oncol 23: 6271-6273, 2005; author reply 6273-6274

36. Lin $\mathrm{CH}$, Yen RF, Jeng YM, et al: Unexpected rapid progression of metastatic adenoid cystic carcinoma during treatment with imatinib mesylate. Head Neck 27:1022-1027, 2005

37. Ochel HJ, Gademann G, Rocken C, et al: Effects of imatinib mesylate on adenoid cystic carcinomas. Anticancer Res 25:3659-3664, 2005

38. Pfeffer MR, Talmi $Y$, Catane R, et al: A phase II study of Imatinib for advanced adenoid cystic carcinoma of head and neck salivary glands. Oral Oncol 43:33-36, 2007

39. Hotte SJ, Winquist EW, Lamont E, et al: Imatinib mesylate in patients with adenoid cystic cancers of the salivary glands expressing c-kit: A Princess Margaret Hospital phase II consortium study. J Clin Oncol 23:585-590, 2005

40. Glisson BS, Blumenschein G, Francisco M, et al: Phase II trial of gefitinib in patients with incurable salivary gland cancer. J Clin Oncol 23:508s, 2005 (suppl; abstr 5532)

41. Haddad R, Colevas AD, Krane JF, et al: Herceptin in patients with advanced or metastatic salivary gland carcinomas: A phase II study. Oral Oncol 39:724-727, 2003
42. Argiris A, Goldwasser MA, Burtness B, et al: A phase II trial of PS-341 (bortezomib) followed by the addition of doxorubicin at progression in incurable adenoid cystic carcinoma of the head and neck: An Eastern Cooperative Oncology Group study. J Clin Oncol 24:298s, 2006 (suppl; abstr 5573)

43. Rugo HS, Herbst RS, Liu G, et al: Phase I trial of the oral antiangiogenesis agent AG-013736 in patients with advanced solid tumors: Pharmacokinetic and clinical results. J Clin Oncol 23:5474-5483, 2005

44. Xia W, Mullin RJ, Keith BR, et al: Anti-tumor activity of GW572016: A dual tyrosine kinase inhibitor blocks EGF activation of EGFR/erbB2 and downstream Erk1/2 and AKT pathways. Oncogene 21: 6255-6263, 2002

45. Spector NL, Xia W, Burris H III, et al: Study of the biologic effects of lapatinib, a reversible inhibitor of ErbB1 and erbB2 tyrosine kinases, on tumor growth and survival pathways in patients with advanced malignancies. J Clin Oncol 23:2502-2512, 2005

46. Chiu KY, Loke SL, Ho FC: Immunohistochemical demonstration of c-erbB-2 oncoprotein in gastric adenocarcinoma: Comparison of cryostat and paraffin wax sections and effect of fixation. J Clin Pathol 47:117-121, 1994

\section{Acknowledgment}

We thank Doris A.E. Parolin and Trudey Nicklee for their assistance with the pharmacodynamic assessments on the paired biopsy samples.

\section{Appendix}

The Appendix is included in the full-text version of this article, available online at www.jco.org. It is not included in the PDF version (via Adobe ${ }^{\circledR}$ Reader ${ }^{\circledR}$ ). 